\title{
Sobre convenções em torno de argumentos de autoridade
}

\author{
Maria Margaret Lopes**
}

\begin{abstract}
Resumo
Partindo de um recorte de leituras do campo disciplinar de História das Ciências, este artigo reúne flashes da construção e da diversificação das áreas de estudos identificadas como gênero e ciência, gênero em ciências, estudos feministas das ciências, para problematizar a importância de se considerar a historicidade desses estudos de gênero e suas contribuições e limitações para reflexões críticas sobre a construção das ciências.
\end{abstract}

Palavras-chave: História das Ciências, Gênero em ciências, Estudos feministas das ciências, Objetividade.

\footnotetext{
* Recebido para publicação em janeiro de 2006, aceito em março de 2006. Este artigo faz parte de uma pesquisa mais ampla sobre a trajetória feminista-científica de Bertha M.J. Lutz, desenvolvida no projeto Temático FAPESP Gênero, Corporalidades, coordenado por Mariza Corrêa.

** Professora do Instituto de Geociências e pesquisadora do Núcleo de Estudos de Gênero - Pagu, ambos na Unicamp, Campinas, São Paulo. mmlopes@ige.unicamp.br
}

cadernos pagu (27), julho-dezembro de 2006: pp.35-61. 
Sobre convenções

\title{
Conventions on Authority Claims
}

\begin{abstract}
By means of readings of the disciplinary field of History of Science, this paper presents "flashes" of the construction and diversification of areas of studies identified as gender and science, gender in science and feminist studies of science, to problematize the importance of considering the historicity of these gender studies and their contributions and limitations in the critical appraisal of the contruction of sciences.
\end{abstract}

Key Words: History of science, Gender Inside Science, Feminist Science Studies, Objectivity. 
Maria Margaret Lopes

\section{Gênero}

Este artigo traz algumas reflexões sobre gênero em História das ciências. Tem sua inspiração primeira em Antropólogas $e$ Antropologia. Retomado aqui como um argumento de autoridade, este é um daqueles livros que a gente sempre pensa que gostaria de ter escrito. Como incentiva Mariza Corrêa, a discussão que se segue pretende ser mais um

esforço de começarmos a compreender a atuação contextualizada de algumas de nossas ilustres antepassadas [para nos ajudar]... na compreensão dos movimentos complexos e sutis de construção de gênero cultural, histórica e politicamente determinados nos quais... estamos envolvidas. (Corrêa, 2003:207)

As ciências naturais assumiram uma autoridade inigualável nas culturas ocidentais nos últimos séculos. Os questionamentos das bases dessa autoridade cognitiva proliferaram a partir da segunda metade do século XX nos estudos históricos, sociológicos, filosóficos, nas críticas de teóricas feministas, mas não mobilizaram de forma mais densa e articulada os estudos de gênero em História das Ciências no país. Diferentemente de outras áreas das ciências humanas - em História das Ciências, no Brasil, apesar de iniciativas anteriores, só muito recentemente gênero começou a ser incorporado de forma mais ampla como uma perspectiva de abordagem teórica e possível linha de pesquisa sancionada institucionalmente. ${ }^{1}$

\footnotetext{
${ }^{1}$ Nas reuniões da Sociedade Brasileira de História da Ciência (SBHC) apenas começam a ser incorporados mesas e simpósios temáticos sobre gênero e ciências e a partir de 2005, viabilizou-se o programa Mulher e Ciência da Secretaria Especial de Políticas para Mulheres, que culminou com o edital do $\mathrm{CNPq}$, a premiação para monografias nos diferentes níveis de ensino e a realização de um encontro nacional.
} 
Sobre convenções

Nas Histórias das Ciências elaboradas no mundo norteatlântico, gênero foi construído enfrentando entre inúmeros aspectos, a questão de que as atividades das mulheres diferentemente das atividades dos homens, permaneceram e têm permanecido fora das análises do mainstream das culturas ocidentais. Nos últimos 30 anos as reflexões em torno da subrepresentação das mulheres nas ciências ou mesmo, em determinados contextos específicos, sua exclusão das práticas $e$ instituições científicas, ganharam enorme consistência teórica $e$ empírica, através das discussões de como gênero tem sido um fator significativo na estruturação das instituições e práticas científicas e como as hierarquias de gênero têm direcionado pesquisas e moldado prioridades e teorias científicas. (Schiebinger, 2003)

Tais estudos têm explicitado que a exclusão não significa, necessariamente, que essas atividades não ocorreram, não foram importantes, ou particularmente, não foram ciências. (Ginzberg, 1989) A exclusão das mulheres das diferentes abordagens sobre as práticas científicas em momentos da História, apenas significa que as mulheres $e$ as atuais perspectivas de gênero não mereceram como muitos homens e outras abordagens analíticas ${ }^{2}-$ a atenção devida dos integrantes das culturas hegemônicas das mais diferentes áreas disciplinares.

\footnotetext{
${ }^{2}$ Nos últimos já quase 30 anos, foi construída toda uma vasta historiografia sobre as ciências - com pouca reflexão sobre gênero - produzidas nos países não norte-atlânticos, incluindo a América Latina. (Lopes, 1998, 2001) Como as mulheres que praticaram ciências, também na América Latina, essa literatura permanece não incorporada nas produções referenciais da bibliografia da História das ciências dos considerados centros de produção. Volumes recentes da Osiris, ISIS e Science in Contex podem ser apontados como iniciativas pontuais de alguma atenção a essa produção, que, no entanto, circula regularmente em congressos e encontros nacionais $e$ internacionais. Talvez menos em relação à história da Medicina, grande parte dessa produção em história das ciências naturais, apesar de desenvolvida nos próprios espaços acadêmicos da disciplina História, também permanece ainda pouco incorporada nas análises históricas gerais sobre o Brasil.
} 
Apesar de inúmeros avanços, particularmente no que se refere ao reconhecimento das especificidades e localidades da produção de conhecimentos científicos, gênero - como um conceito historicamente datado - permanece de difícil assimilação no campo da História das ciências no Brasil. É, no entanto um conceito que poderia ser entendido a partir de um paralelo com o conceito de paradigma. Se sujeitássemos boa parte dos textos das teóricas feministas ao escrutínio que Margaret Masterman (1979) ${ }^{3}$ fez do livro de Kunh (1962), talvez chegássemos até mesmo a um total maior para a quantidade de possíveis empregos do termo em cada texto.

Suas múltiplas abordagens e imprecisões o tornam útil, particularmente após o fantástico aumento dos estudos de gênero das últimas décadas, que foram acompanhados de uma certa perda de definição. Gênero como um conceito multifacetado, tem quase uma existência orgânica para Ludmilla Jordanova. Alterna camadas de significados, do mesmo modo como os estratos geológicos que se superpõem, são erodidos, destruídos pelo tempo e novamente depositados em processos diagenéticos não necessariamente, calmos. O conceito inevitavelmente apoiado em uma maneira dual de pensar permite identificar a persistência desse dualismo engendrado, por longos períodos de tempo, enquanto sua história - recente - alerta de que não se trata de mais um conceito necessariamente universal $e$ atemporal. (Jordanova, 1999:7-9) Como um conceito relacional, implicando que atributos masculinos e femininos sejam definidos um em relação ao outro, pressuporia também que termos como sexual, feminino, masculino não fossem tomados como auto-evidentes, mas sim também considerados em sua historicidade. (Jordanova, 1989) Como Ludmilla Jordanova ainda nos lembra, gênero é um

\footnotetext{
${ }^{3}$ No auge das discussões sobre o termo em 1965, a autora contou 21 sentidos diferentes em que o conceito de paradigma foi empregado só na obra fundamental de Kuhn.
} 
Sobre convenções

tópico sedutor e importante, mas também um conceito extremamente difícil de ser trabalhado.

Essas dificuldades se entrelaçam a aspectos da própria história da construção do conceito de gênero. Relacionam-se muito mais ao não questionamento das idéias de universalidade, neutralidade e objetividade das ciências, que permanecem ainda amplamente referendadas (mesmo entre teóricas feministas, estudiosos de gênero e muitos historiadores das ciências), do que à não operatividade do conceito para a construção de historicidades locais. Sua maior assimilação no país, nos estudos de caráter cientométrico, restringindo muitas vezes o conceito a uma variável empírica - acompanhando o que muitas vezes se faz com raça/etnia, classe, religião -, embora tenha total relevância, é em muitos casos mais uma evidência dessas dificuldades.

\section{Gênero e Ciências}

Os termos conjugados gender and science apareceram pela primeira vez em 1978, como o título de um artigo em que Evelyn Fox Keller (1978), considerava as relações entre subjetividade e o que ela definia como "objetividade dinâmica", por oposição à "objetividade estática". A partir de uma argumentação psicanalítica, a autora identificava uma "associação historicamente onipresente" entre masculino e objetivo, caracterizada por ter simultaneamente um "ar de auto-evidente" no âmbito do conhecimento comum e por "não ter sentido" no âmbito do conhecimento científico. O silêncio virtual sobre o tema lhe sugeria que a associação entre masculinidade e pensamento científico, possuía status de um mito que ou não podia ou não devia ser investigado a sério, uma vez que entrava em conflito com nossa imagem da ciência sexual e emocionalmente neutra. Considerando o conceito de objetividade como a busca de um entendimento do mundo que nos rodeia, como o mais autêntico possível, e por isso o mais fiável possível, Fox Keller considerava que a objetividade dinâmica era a busca de conhecimento que 
fizesse uso da experiência subjetiva em interesse de uma objetividade mais efetiva, em oposição à objetividade estática, que se caracterizaria pela busca de conhecimento que se inicia pela separação entre sujeito e objeto, sem tentar desvendar as intrincadas uniões que se produzem entre um e outro.

Na década de 1990, referindo-se à origem, história e política do tema, que rapidamente ganhou dimensões internacionais, a autora considerava que gender and science havia se tornado cada vez mais problemático. Evelyn Fox Keller $(1992,1995)$ referia-se a três linhas de investigação: mulheres na ciência, construções científicas de gênero e influência do gênero nas construções históricas da ciência. Revisando a expansão das pesquisas, cursos, textos sob essa denominação, a autora, admitindo que o campo já havia proliferado profusamente e traçado uma variedade imensa de caminhos de pesquisas, considerava que a única coisa que mantinha esse agrupamento diversificadíssimo unido era sua ativa resistência ao desaparecimento do gênero (e, é claro das mulheres). Avaliando de forma crítica, mas considerando também os aspectos positivos dessa diversificação de sentidos assumida pelo campo disciplinar, Evelyn Fox Keller afirma que de certo modo gender and science representa a realização de um dos objetivos que foi central para os estudos feministas em seus primeiros anos, qual seja a interação de insigths e métodos feministas a outras abordagens convencionalmente mais familiares aos meios acadêmicos. (Fox Keller, 2001)

Há algum tempo, estão muito mais nuançadas as visões presentes, particularmente no debate norte-americano dos anos de 1980-90 (Kohlstedt e Longino, 1997), em que correntes advogavam que refletir sobre "mulheres na ciência" era uma conceituação utilizada para silenciar a função historicamente social, política $e$ cognitiva das normas de gênero no sistema das ciências. Evelyn Fox Keller referiu-se a essa discussão, em outra retrospectiva da área dos estudos de gender and sciences - que contribuiu decisivamente para conformar-, pelo deslocamento de centros de 
Sobre convenções

interesse e não pela oposição entre perspectivas analíticas $e$ conceituais:

O centro de interesse não era a presença ou ausência das mulheres nas ciências, mas as maneiras pelas quais as imagens tradicionais de gênero puderam (involuntariamente) conformar a própria atividade científica: tratava-se de se interrogar sobre os recursos cognitivos, emocionais e humanos perdidos pela ciência porque tinham a característica de serem etiquetados como "femininos" e por isso sido excluídos. Poderia sublinhar que a intenção por trás da nossa pesquisa (a minha pelo menos) era desde o início uma intenção amigável, tanto em relação à ciência como às mulheres. Meu objetivo era liberar a ciência $e$ as mulheres das cadeias de uma ideologia debilitante sobre gênero. (Fox Keller, 2000:45-57)

Mais de uma vez a autora reiterou o quanto se esforçava com outros colegas para articular e ocupar uma posição intermediária entre os estudos sociais das ciências que no seu entender tendiam para uma dissolução de todas as fronteiras delimitadoras das ciências na direção de estudos contextualistas culturais, de linguagem, institucionais, políticos e sua inclinação, cada vez maior, para a necessidade de maior atenção às amarras lógicas e empíricas que tornam as assertivas científicas tão determinantes para os cientistas, como as proezas tecnológicas que as tornam tão determinantes para o mundo como um todo. (Fox Keller, 1992:3)

\section{Objetividades}

As recentes teorias feministas, que podem ser entendidas como fornecedoras de alternativas críticas para as narrativas convencionais sobre as ciências, ironicamente contribuíram para uma revitalização da história das idéias, reconhece a própria Evelyn Fox-Keller (1996:418). Caminharam na contramão de movimentos contemporâneos em que as disciplinas da história das 
ciências, da tecnologia da medicina ${ }^{4}$ - na crítica às interpretações tradicionais em que as idéias flutuavam livremente em espaços conceituais (Shapin, 1996) - avançavam velozmente na busca de maiores e mais amplas contextualizações de temporalidades, localidades e caracterizações da diversidade das culturas tecnocientíficas.

Em nome da ação afirmativa e da delimitação de novas áreas acadêmicas de autoridade científica, muitas teóricas feministas norte-americanas não se propuseram a desafiar o "ethos" mertoniano da universalidade, objetividade, neutralidade das ciências. ${ }^{5}$ Outras, problematizando a neutralidade de gênero das ciências no campo dos estudos feministas da ciência (feminist science studies), inseriram-se nas discussões abrangentes dos anos de 1980 e 1990 envolvendo diversos campos disciplinares que questionaram $\mathrm{o}$ atributo epistemologicamente superior que a ciência construiu para si própria, fortemente alicerçado na ênfase em sua objetividade. A busca por "objetividades dinâmicas", "objetividades fortes" atemporais enredou muitas das teóricas feministas, que para consolidarem a delimitação do próprio campo de estudos adotaram uma ambivalência estratégica de recusa tão firme, ao que consideraram um construtivismo reducionista, quanto assumiram uma rejeição a um objetivismo não reflexivo (Conkey, 2003) difícil de ser defendido e entendido.

No âmbito da crítica feminista às ciências, Sandra Harding buscou uma apropriação do conceito de "objetividade forte", numa alusão ao "programa forte" dos estudos sociais das ciências. As propostas das epistemologias do ponto de vista feminista que tiveram seguidoras famosas como Donna Haraway ${ }^{6}$ foram

4 Para uma discussão mais ampla das perspectivas metodológicas unificadoras abrangendo História das Ciências, Tecnologia e Medicina, com as quais muitas historiadoras feministas das ciências se identificam, ver Pickstone, 1994.

${ }^{5}$ Essa é uma das críticas que se atribui ao feminismo liberal norte-americano. (Schiebinger, 2001)

${ }^{6}$ Ver, neste volume dos cadernos pagu, outras referências às posições de Donna Haraway. Ver também Haraway, 1995, 2004. 
Sobre convenções

amplamente questionadas particularmente no que se refere ao não questionamento da centralidade $e$ atemporalidade do conceito de objetividade para as ciências. Considerando-se que a orientação masculina em relação às ciências é sistematicamente distorcida, assumiu-se muitas vezes que a perspectiva feminista teria mais condições de produzir conhecimento objetivo válido.

Assim não só as críticas às estruturas masculinas de conhecimento são salvas, guardadas, como se preserva a possibilidade de alguma forma de ciência e, em particular, de uma ciência exclusivamente feminista. (Gergen, 1993:48-

69)

Outras problematizações em torno da construção do conceito de objetividade, tais como as discussões envolvendo as práticas situadas de campo (Oreskes, 1996) e os avanços na compreensão de sua historicidade indicaram desdobramentos mais contextualizados e profícuos para a discussão, esvaziando de certo modo este que foi um tema central de algumas das mais proeminentes teóricas feministas. A partir das discussões sobre as áreas do conhecimento que têm no campo seus loci privilegiados de construção de saberes, Naomi Oreskes se perguntou o quanto na verdade as noções de objetividade científica são centrais para a construção das ciências. Desvinculou da questão da objetividade científica sua análise da prática da geofísica Eleanor Lamson - que desempenhou com todo rigor seu papel na obtenção das primeiras medidas de gravidade submarinas norte-americanas no início do século XX - foi reconhecida por seus pares $e$ desapareceu como outras tantas da historiografia. Propôs considerar que o problema da objetividade nas ciências de campo e suas decorrências - como a possível invisibilidade das mulheres - fosse reinterpretado em um contexto mais abrangente que incorporasse a questão do heroísmo científico.

Nesse âmbito do heroísmo - imagem menos conectada com qualquer virtude particular atribuída à ciência, mas fortemente 
associada aos ideais de masculinidade da cultura moderna européia - se pode reconhecer melhor causas epistemológicas da invisibilidade das mulheres em ciências. Estas estariam pouco relacionadas com os problemas da "objetividade" como tradicionalmente entendida, já que nas visões de ciências que se apoiam no conceito de objetividade há um espaço limitado para se considerar temas como exclusão e invisibilidade de gênero, de pontos de vista teóricos e epistemológicos. ${ }^{7}$

Lorraine Daston \& Peter Galison (1992) e Peter Dear (1992), entre outros autores não inseridos exatamente no campo disciplinar do gênero, discutiram as complexidades da história da subjetividade científica evidenciando como o conceito de objetividade, que não é monolítico nem imutável, muito menos atemporal emergiu enquanto conceito historicamente datado no final do século XVIII, para se estender às ciências naturais somente no meados do XIX, como resultado da reorganização da profissionalização e internacionalização da vida científica. Reconhecendo tais contribuições Evelyn Fox Keller, que como outras teóricas avançou para os estudos da linguagem e das metáforas nas ciências lembrou como na segunda metade do século XIX, a "subjetividade" do narrador - na primeira pessoa do texto científico pôde efetivamente ser substituída pela "objetividade" do "cientista" abstrato que podia falar por todos os homens (as mulheres não estavam ainda massivamente nas instituições de ensino e pesquisa européias e norte-americanas), ao mesmo tempo, que era um não-homem em um duplo sentido: não era nenhum homem em particular, mas era um locus para o não homem em cada e todo observador singular. (Fox Keller, 1996:419)

Exemplificando quanto os já cientistas do XIX sacrificaram com plena consciência sua busca da verdade ao que se passou a convencionar como objetividade, Lorraine Daston chama a

7 Retomo aqui essa discussão apresentada em artigo anterior. (Lopes, Sousa e Sombrio, 2004) 
Sobre convenções

atenção para a complexidade conceitual de seus entendimentos contextualizados e de suas múltiplas formas, muitas vezes conflitantes entre si. Argumentando que a objetividade científica tem uma história, - relativamente curta, por sinal -que existe mais de uma espécie de objetividade científica e que as diferentes objetividades não são apenas distintas entre si, mas por vezes se encontram em conflito, Daston recorre à etimologia da palavra, aos seus múltiplos sentidos presentes em Descartes, Kant para identificar a própria objetividade como plural e preferir o uso de "objetividades científicas" em suas análises das objetividades mecânica da fotografia e comunitária do mapa. Para Daston se o medo de que aspectos do "eu" ameacem perigosamente o conhecimento é uma tradição muito antiga, preferir a objetividade - como prática e como ideal científico - a outras virtudes epistemológicas como a verdade ou a certeza foi uma escolha tardia, que se contrapôs ao regime setecentista da "fidelidade à natureza" ${ }^{8}$, que retomaremos à frente.

Autoridade científica, sexo-gênero, corpos

Na demarcação das identidades do novo campo disciplinar $e$ em seus processos de validação institucional, os Feminist Science Studies ${ }^{9}$ avançaram seguindo passos semelhantes aos seus campos disciplinares aparentados, science studies e história e filosofia das ciências embora cada um continuasse e continue se desenvolvendo como uma disciplina específica por si própria

8 A título de exemplo, os astrônomos do século XIX denominavam as idiossincrasias na observação de "equação pessoal" do observador individual, que podiam tender para um rigor acima ou abaixo da média. Adotar a objetividade incorporada nos instrumentos científicos pode significar sacrificar a objetividade incorporada nos métodos estatísticos de análise, isto é, sacrificar a impessoalidade da observação ao rigor da observação. (Cf. Daston, 1999:83)

9 Creager, Lunbeck, Schiebinger, 2001:1-19. Nos esforços de validação do campo disciplinar, as autoras reconhecem sua fragmentação entre os estudos de gênero e ciências isolados daqueles de gênero e tecnologia, os quais têm sido formulados à parte das analises feministas sobre a medicina. 
(Schiebinger, 2003; Citeli, 2000), embora evidentemente não tenham faltado esforços de fertilizações cruzadas entre as áreas disciplinares, que têm se mostrado dos mais promissores. Em comum continuam partilhando a dificuldade de que seus insights e métodos façam incursões mais profundas nas ciências. Evidentemente pela rejeição dos cientistas naturais, mas também fundamentalmente pela não incorporação das reflexões sobre as ciências $e$ as tecnologias nas agendas prioritárias dos estudos de gênero, particularmente no nosso caso.

Falar em constituição e demarcação de campos disciplinares requer lembrar que o valor da autoridade científica se apóia, precisamente, na defesa das fronteiras entre e intra-disciplinares contra possíveis intrusões indesejadas. ${ }^{10} \mathrm{E}$ foi justamente na demarcação de campos disciplinares que gênero se consolidou no âmbito das ciências humanas como construto cultural em oposição ao sexo como "fato" ${ }^{11}$ da esfera das ciências naturais:

O que exatamente aconteceu foi que as feministas introduzindo a distinção sexo gênero reproduziram a tradicional divisão de tarefas entre as ciências sociais $e$ biomédicas. As feministas consignaram o estudo do sexo para o domínio das ciências biomédicas e definiram o estudo de gênero como domínio exclusivo das ciências sociais. (Oudshoorn, 2001:200).

Em seus múltiplos entendimentos relacionais foi justamente na oposição ao sexo no sistema sexo-gênero que o conceito

\footnotetext{
${ }^{10}$ Ver, Barnes, Bloor, \& Henry, 1996:140-168, cap. 6 -Drawing Boundaries.

${ }^{11}$ Sobre a construção dos fatos científicos, a obra de Fleck (1935) - que inspirou Thomas Kunh e toda a corrente dos estudos sociais das ciências - é referência obrigatória para o entendimento das dimensões espaciais e temporais da construção do que se negocia e convenciona considerar "fato" científico. Löwy (2000:33), especialista em Fleck, lembra "que os fatos científicos são produzidos por comunidades de praticantes bem definidas que trabalham em lugares determinados. O estudo das práticas dos pesquisadores coloca em evidência, portanto a materialidade e a historicidade da produção científica".
} 
Sobre convenções

operou de forma decisiva para o avanço de abordagens menos descritivas, consolidando-se como uma categoria analítica de reconhecida utilidade para as abordagens históricas. Atribuído a diversas maternidades - o que só significa que sua densidade conceitual tomou corpo no início dos anos de 1970 -, o sistema sexo-gênero na formulação pioneira de Ann Oakley (1972) enfatizou de forma insistentemente duradoura a relevância de se distinguir "biological, innate sex differences" e "gender attributes that are acquired by socialization".

No auge de suas críticas internacionais, nos anos de 1990, mantendo a divisão ciências naturais/ciências humanas o sistema sexo-gênero foi atualizado no Brasil, por traduções de teóricas feministas dos mais diversos matizes - de Sandra Harding ${ }^{12}$ a Gayle Rubin. ${ }^{13} \mathrm{O}$ tão útil sistema sexo-gênero - o sexo naturalizado e incorporado pelas teóricas feministas - como categoria biológica e só gênero entendido como uma construção no âmbito da cultura permanece ainda presente de forma marcante, mesmo que implicitamente, em muitos dos textos importantes sobre gênero nas reflexões no Brasil, que persistentemente ignoram todos os esforços e avanços das análises que há muito tempo situam a construção das ciências naturais, biomédicas no âmbito das culturas científicas.

\footnotetext{
${ }^{12} \mathrm{Na}$ nota 1 do primeiro capítulo do seu livro, The Science Question in Feminism, Sandra Harding explica que estabelece uma drástica distinção entre sexo e gênero, ainda que vá retomar no livro, os problemas dessa dicotomia e insiste na utilização de "sexo, quando se trata de questões meramente biológicas" em função de suas ressalvas frente ao fascínio exercido então pela sociobiologia, $e$ para evitar incompreensões $e$ hostilidades $e$ incompreensões frente às abordagens de gênero. (Harding, 1996)

${ }^{13}$ Gayle Rubin foi traduzida pelo SOS-Corpo de Recife em 1993 (draft). Embora assinalando que "a autora pensa em termos universais e opera com uma série de dualismos - sexo/gênero, natureza/cultura - que se tornarão alvo das críticas feministas posteriores", Adriana Piscitelli encontra deslocamentos significativos nas formulações dessa autora que será bastante influente nos estudos de gênero no Brasil. (Piscitelli, 2002:19).
} 
Maria Margaret Lopes

\begin{abstract}
Embora o conceito de gênero tenha sido desenvolvido para contestar a naturalização da feminilidade, acontecia o oposto. As teorias feministas da socialização não questionaram o sexo biológico daqueles sujeitos que se tornaram socializados como mulheres; elas assumiram sexo e o corpo como imutáveis realidades biológicas que não necessitavam de maiores explicações. Nesses estudos o conceito de corpo sexuado manteve seu status de uma base a-histórica, não problemática sobre a qual gênero é inscrito. Consequentemente, o corpo permaneceu excluído das análises feministas. ${ }^{14}$
\end{abstract}

Enquanto em certos campos do feminismo se intensificaram as discussões em torno da polaridade natureza/cultura, pelo menos os corpos femininos, começaram a ser entendidas como historicamente contingentes. Historiadoras e antropólogas começaram a desafiar a noção de um corpo natural, desde os anos de 1980. Biólogas feministas, historiadoras e filósofas das ciências, como Ruth Bleir (1984), Ruth Hubbard (1993), Evelyn Fox Keller (1985) e Helen Longino e Ruth Doel (1983) ${ }^{15}$ - em "movimentos cruciais de exposição do mito do corpo natural" sugeriram que os "fatos" anatômicos, endocrinológicos ou imunológicos são qualquer coisa, menos auto-evidentes:

Nós não podemos falar do corpo feminino como se ele fosse uma presença invariante através da história. Não existe uma base fixa, experimental, que forneça tal continuidade através dos séculos. ${ }^{16}$

\footnotetext{
${ }^{14}$ Oudshoorn, 2001:200. Para outras leituras da obra clássica de Oudshoorn (1994), ver Citeli, 2006. Ver também a resenha de Maria Conceição da Costa neste número dos cadernos pagu.

${ }^{15}$ Para uma resenha instigante desses textos, ver Fausto-Sterling (1986) e os comentários que estamos seguindo de Oudshoorn (2001:201).

${ }^{16}$ Ver essa citação de Jacobus, Fox Keller and Shuttleworth (eds.), Body/Politics: Women and the Discourses of Science. New York/London, Routledge, 1990:4, em Oudshoorn, 1994:201.
} 
Sobre convenções

Muitos desses poderosos insigths analisaram experiências com o corpo e como essas experiências foram moldadas $e$ marcadas por suas diferentes temporalidades e culturas. Muitos deles, no entanto, continuaram se referindo a uma realidade universal, fisiológica, a temas biológicos tratados como não históricos. Nessas abordagens experienciais, a facticidade e a autoevidência dos fatos biológicos sobre o corpo permaneceram não desafiados, no entender de Nelly Oudshoorn (1994), que excetuava dessas considerações o texto clássico de Emily Martin (1987).

Nesse seu texto fundacional a que vimos nos referindo, avançando de suas primeiras considerações para o questionamento de quanto o corpo masculino ainda permanecia como categoria "estável", intocada pelo tempo e lugar, nos discursos feministas que mantinham o corpo masculino em sua naturalidade - "o corpo masculino não é um construto; ele simplesmente existe" - Nelly Oudshoorn aprofundou as discussões em torno do quanto as feministas involuntariamente reproduziram a tradição do discurso médico que apresenta os corpos femininos como o outro a ser explicado para existir. Refletindo sobre as estratégias perseguidas pelas feministas nas quais se inclui, em suas críticas às noções essencialistas do corpo e incorporando perspectivas de análises dos estudos sociais das ciências, parafraseava o título do conhecido artigo de Bijker - "não se desespere; existe vida depois do construtivismo para a política feminista, mesmo dentro da corrente principal da arena discursiva". (Oudshoorn, 2001:210; Bijker, 1993)

No âmbito da História das Ciências norte-americana e inglesa muitos dos estudos de gênero também se dirigiram para as análises das ciências encarnadas, incorporadas ${ }^{17}$, para a compreensão da apropriação por esse campo disciplinar das influências dos estudos de cultura científica sobre corporalidades,

${ }^{17}$ Ver, por exemplo, a bibliografia de referência e as discussões reunidas na coletânea editada por Lawrence \& Shapin (1998). 
que o marcaram desde os anos de 1980, 1990. A vida continuava $e$ se diversificava nas análises das contextualidades e historicidades dos corpos. Corpos - sexuais, simbólicos das nações e revoluções, de conhecimentos, construídos pelos discursos biomédicos, separados das mentes nas teorias cartesianas, problematizados nas imagens, etc. - ganharam proporções inusitadas nas diferentes áreas disciplinares nos últimos 20 anos. Os corpos procuraram um lugar metodológico na História do gênero através de suas potencialidades e limitações. (Canning, 1993) Os corpos e suas histórias foram questionados e tornados incomensuráveis enquanto propostas teóricas, por operarem com bases em hipóteses totalmente diversas para se constituírem em corpo conceitual único, transdisciplinar, no provocativo artigo da historiadora Carolyn Walker Bynum (1995) que vai a Idade Média para discutir "Why all the Fuss about the Body?".

Os corpos femininos retrataram a natureza no regime setecentista de fidelidade à natureza de que falava Lorraine Daston, que pressupunha a subjetividade da projeção do sujeito na natureza, incluindo o juízo científico e a idealização estética. Uma vez que as verdades da natureza eram universais $e$ permanentes e os nossos vislumbres delas passageiros e variáveis, anatomistas e botânicos, astrônomos e geólogos, do XVIII ao início do XIX, editaram escrupulosamente suas observações $e$ embelezaram suas ilustrações a serviço de um ideal de "fidelidade". (Daston, 1999:85) Tais corpos "tipos" (categoria classificatória da História natural) não apenas típicos, mas ideais, característicos ou ainda "a média" foram invocados pelos naturalistas nas escolhas de suas imagens representativas. Tais corpos datados, em suas personificações das naturezas humanas, animais, do conhecimento, constituíram o foco das análises feministas engendradas sobre as culturas da natureza: desde quando a ciência era mulher no início das ciências modernas ${ }^{18}$,

${ }^{18}$ Schiebinger, 1989:119-159, especialmente o capítulo 5 - Battles over Scholarly Style. 
Sobre convenções

até quando as metáforas e analogias baconianas ${ }^{19}$ alcançaram os corpos minerais, justificando a exploração $e$ a escavação não mais da mãe Terra, mas da verdadeira madrasta que escondia seus segredos em suas entranhas. ${ }^{20} \mathrm{Ou}$ ainda, quando a natureza era exibida em suas variações sazonais no Ladies garden por torsos femininos. Garden, como explica Jordanova, no final do XVIII na Inglaterra era uma gíria humorística não exatamente obscena para as partes sexuais das mulheres e nessas imagens femininas, sexualidade e reprodução eram associadas como funções naturais, evocadas pelas plantas e jardins, pelos ritmos da natureza que se repetiam. Nessas imagens poderosas, as identidades entre idéias de feminilidade e natureza, assim como suas ambivalências eram evidentes. Os corpos femininos simultaneamente eróticos $e$ perturbadores foram firmemente inseridos no domínio da natureza. ${ }^{21}$

Valendo-se de importantes aportes da história cultural - não por coincidência o interesse por gênero ocorreu simultaneamente à proliferação da história cultural ${ }^{22}$ - Ludmilla Jordanova (1989) partindo da crença de que as idéias científicas podem ser entendidas como mediações, reconhecia que nos séculos XVIII $e$ XIX as ciências biomédicas foram marcadas por múltiplos significados e passaram por intrincadas transformações, mediadas por papéis sexuais, diferenças de gênero, mudanças sociais.

${ }^{19}$ Para uma análise de gênero da importância das metáforas baconianas na constituição das ciências modernas, o texto de Fox Keller (1985) permanece como o referencial indispensável.

${ }^{20}$ Merchant (1980:170-171), em sua análise da "Revolução científica", considera entre inúmeros outros aspectos a mudança na linguagem dos mineradores, as metáforas masculinas das modernas mitologias das conquistas, empregadas por Bacon em sua nova Filosofia Natural.

${ }^{21}$ Jordanova, 1999, especialmente o cap. 2 - Femine Figures: Nature Display'd, da parte I Natural Polarities.

${ }^{22}$ Hunt (2001) ressalta a importância do gênero no desenvolvimento dos métodos da história da cultura em geral, lembrando a prioridade que os estudos de gênero assumiram na nova história cultural particularmente nos Estados Unidos. 
Robert Martensen apoiado nas doutrinas influentes na Inglaterra no XVII e XVIII, do significado dos fluídos, dos corpos neurocêntricos - que distanciaram ainda mais a mente (agora firmemente estabelecida no cérebro) do corpo - analisa as imagens de órgãos sexuais masculinos e femininos de Vesalius $e$ outros textos pré-iluministas, como ao mesmo tempo similares e diferentes, podendo ser igualmente relativas a um sexo ou a dois, complexificando e argumentando contra o sistema de sexo único que Thomas Laqueur (1990) tão bem historicizara e trouxera definitivamente para a esfera das construções das culturas científicas. Para Martensen

a convergência de um paradigma corporal, que enfatizava o primado das partes sólidas do cérebro e as estratégias epistemológicas e teológicas que enfatizavam a natureza masculina da investigação "sólida" que conduzira a esse paradigma, constituiu um homoerotismo explícito que constrangeu seriamente a mulher (e o feminino) em cada nível do seu ser. (Martensen, 1998: 151)

Londa Schiebinger trouxe para as discussões de gênero as classificações sexuais lineanas das plantas e dos mamíferos naturalizados em substituição aos antigos quadrúpedes, em meio a todo o engajamento de Lineu em campanhas racistas pelo aleitamento materno. (Schiebinger, 1993) O reconhecimento da força das imagens (em si constitutivas da História Natural) engendrou em profundidade as análises da disciplina, que permanecendo vista como uma prática próxima ao domínio público, aberta e igualitária que desfrutava de um status único entre as ciências naturais por todo o século XVIII, especialmente na França (Drouin e Bensaude-Vincent, 1997), permitiu inclusive o acesso das próprias mulheres a outros jardins - no caso públicos -, possibilitando também um campo de análise fértil para os estudos sobre aquelas que se profissionalizavam em uma das disciplinas que primeiro abrigou mas também fez sair as mulheres ao longo do XIX, particularmente na Inglaterra. (Shteir, 1996) O século XVIII 
Sobre convenções

discutiu entre inúmeras questões também aquela de quem poderia fazer ciências. O berço e a herança - princípios regulamentadores do Antigo Regime -, que viabilizaram espaços de poder para mulheres, não foram transferidos para as ciências, como já apontaram diversos autores. Os princípios regulamentadores da nova democracia das práticas científicas pressupunham a freqüência a Academias e obtenção de certificados conferidos por Universidades onde a entrada de mulheres foi na maioria das vezes explicitamente vetada. Por sua vez, a institucionalização da História da Ciência - uma história de como uma disciplina emergiu no início do século XX como defensora da noção da superioridade cultural da civilização ocidental através da ciência, invisibilizaria as mulheres.

Nas análises pioneiras e de caráter externalista de Margaret Rossiter (1982) a busca das mulheres cientistas norte-americanas das décadas de 1880 e 1890 (por volta de 1910 elas já estavam firmemente estabelecidas em alguns campos disciplinares) por reconhecimento científico e por espaços para exercerem suas profissões foi um dos aspectos desveladores da inconsistência das análises mertonianas da universalidade e neutralidade das ciências especialmente em termos de garantia de acesso. Evitando estratégias de confrontos e disputas por áreas de pesquisa de maior concorrência, as mulheres escolheram serem incorporadas ao mercado de trabalho científico de forma segregada incorporando a retórica conservadora dos estereótipos atribuídos aos papéis femininos de "habilidades especiais", "talentos únicos". Em um mundo de trabalho que se profissionalizava $e$ burocratizava, graças aos altos financiamentos, as oportunidades de emprego se ampliaram visando inclusive a capacitação para serviços sociais encarados como femininos. Ciências como "Economia Doméstica", envolvendo atividades relacionadas à nutrição, culinária, saúde, higiene, cuidados com as crianças, a infância e o ambiente doméstico, bem como cursos nos colégios agrícolas coeducacionais, responsáveis pelo desenvolvimento da pesquisa em agricultura foram espaços privilegiados que se 
abriram às mulheres para segregá-las. Mantendo-as como técnicas $e$ assistentes, a burocratização das ciências também levou à segregação das mulheres no meio profissional dos museus de História Natural, que no fim do século XIX ainda abrigavam, além de novos departamentos universitários, mulheres cientistas.

Esses breves comentários - acima de tudo indicativos das inúmeras possibilidades de leituras -, longe de serem exaustivos ou de qualquer tentativa de estabelecer o estado da arte de algumas das discussões que marcam o campo dos estudos de gênero em ciências (Lopes e Costa, 2005), já evidenciam quanto os movimentos feministas do final do século XX, trouxeram aportes fundamentais a todo o processo em curso de reflexão crítica sobre a construção das ciências naturais. Evidenciam também quanto ainda nos falta para empreendermos nossas análises sobre as relações de gênero que marcaram as trajetórias daquelas mulheres que pelo menos desde o final do século XIX já estavam formalmente inseridas nos sistemas de ciências e no ensino superior no país. (Lopes, 2006) Em um contexto histórico marcado justamente pela a apologia da autoridade cognitiva inquestionável da ciência, pela crença inabalável na objetividade e racionalidade científicas, nas quais também o movimento feminista internacional se apoiou para reivindicar o acesso das mulheres ao sistema, a aceitação e a disseminação do que posteriormente se considerou uma "ideologia masculina das ciências" não era então necessariamente contraditória com as reivindicações feministas "de nossas ilustres antepassadas".

\section{Referências bibliográficas}

BARNES, Barry; BLOOR, David \& HENRY, J. Scientific Knowledge: A Sociological Analysis. Chicago, The University of Chicago Press, 1996.

BIJKER, Wiebe. Do Not Despair: There is Life after Constructivism. Science, Technology and Human Values 18, 1993, pp.113-129. 
Sobre convenções

BLEIER, Ruth. Science and Gender: A Critique of Biology and Its Theories about Women. Oxford, Pergamon, 1984.

BYNUM, Carolyn W. Why All the Fuss About the Body? A Medievalist's Perspective. Critical Inquiry 22, Autumn, 1995, pp.1-33.

CANNING, Kathleen. The Body as Method? Reflections on the Place of the Body in Gender History. Gender and History, vol. 11, n 3 , nov. 1993, pp.499-513.

CITELI, M. Teresa. Genética, química e anatomia na atribuição de diferenças sexuais. In: SANTOS, Lucy W. et alii. Ciência, Tecnologia e Gênero. Desvelando o feminino na construção do conhecimento. Londrina, IAPAR, 2006, pp.235-270.

Mulheres nas ciências: mapeando campos de estudo. Cadernos Pagu (15), Núcleo de Estudos de Gênero - Pagu/Unicamp, 2000, pp.39-75.

CONKEY, Margaret W. Has Feminism Changed Archaeology? Signs, volume 28, 2003, pp.867-880.

CORRÊA, Mariza. Antropólogas \& Antropologia. Belo Horizonte, UFMG, 2003.

CREAGER, Angela N.H.; LUNBECK, Elizabeth; SCHIEBINGER, Londa. Introduction. In: CREAGER, A; LUNBECK, E.; SCHIEBINGER, L. (eds.) Feminism in twentieth-century science, technology, and medicine. Chicago/London, The University of Chicago Press, 2001, pp.1-19.

DASTON, Lorraine. As imagens da objectividade: a fotografia e o mapa. In: GIL, Fernando. (coord.) A ciência tal qual se faz. Lisboa, Ed. João Sá da Costa, 1999, pp.79-103.

DASTON, Lorraine and GALISON, Peter. The Image of Objectivity. Representations 40, 1992, pp.81-128.

DEAR, Peter. From Truth to Disinterestedness in the Seventeenth Century. Social Studies of Science 22, 1992.

DROUIN, J-M. e BENSAUDE-VINCENT, B. Nature for the people. In: JARDINE, N. et alii (eds.) Cultures of Natural History. Cambridge, Cambridge University Press, 1997, pp.408-425.

FAUSTO-STERLING, Anne. Books Reviews. Reflections on Gender and Science by Evelyn Fox-Keller; Science and gender: A Critique of 
Biology and Its Theories about Women by Ruth Bleier. Signs, vol. 11, $\mathrm{n}^{\circ} 4,1986$.

FLECK, Luwik. Genesis and Development of a Scientific Fact. Chicago, University of Chicago Press, 1935.

FOX KELLER, Evelyn. Making a Difference: Feminist Movement and Feminist Critiques of Science. In: CREAGER, A.; LUNBECK, E.; SCHIEBINGER, L. (eds.) Feminism in twentieth-century science, technology, and medicine. Chicago/London, The University of Chicago Press, 2001, pp.98-109.

. Histoire d'une trajectorie de recherche. De la problématique "genre et science" au thème "langage et science". In: GARDEY, Delphine et LÖWY, Ilana. (orgs.) L'invention du naturel. Les sciences et la frabrication du féminin et du masculin. Paris, Éd. des archives contemporaines, 2000, pp.45-57.

The Dilemma of Scientific Subjectivity in Postvital Culture. In: GALISON, Peter and STUMP, David J. The disunity of Science. Boundaries, Contexts, and Powers. Stanford, Stanford University Press, 1996, pp.417-427.

The Origin, History, and Politics of the Subject Called "Gender and Science". In: JASANOFF, Sheila; MARKLE, Gerald E.; PETERSEN, James C. and PINCH, Trevor. (eds.) Handbook of Science and Technology Studies. Thousand Oaks, Sage Publishing, 1995, pp.8094.

Secrets of Life, Secrets of Death: essays on language, gender and science. NewYork/London, Routledge, 1992

Reflections on Gender and Science. New Haven and London, Yale Univ. Press, 1985.

Gender and Science. Psychoanalysis and Contemporary Tought 1, 1978, pp.409-33.

GERGEN, Kenneth J. A crítica feminista da ciência e o desafio da epistemologia social. In: GERGEN, Mary McCanney. (ed.) $O$ pensamento feminista e a estrutura do conhecimento. Rio de Janeiro, Rosa dos Tempos/Edunb, 1993, pp.48-69.

GINZBERG, Ruth. Uncovering Gynocentric Science. Hypatia, vol. $2 \mathrm{n}^{\circ} 3$, fall 1989. Reprinted TUANA, Nancy. (ed.) Feminism \& Science. Indiana University Press, 1989, pp.69-84. 
Sobre convenções

HARAWAY, Donna. Gênero para um dicionário marxista: a política sexual de uma palavra. Cadernos Pagu (22), Núcleo de Estudos de Gênero - Pagu/Unicamp, 2004, pp.201-246.

Saberes localizados: a questão da ciência para o feminismo e o privilégio da perspectiva parcial. Cadernos Pagu (5), Núcleo de Estudos de Gênero - Pagu/Unicamp, 1995, pp.7-42.

HARDING, Sandra. Ciencia y Feminismo. Madrid, Ediciones Morata, 1996.

HUBBARD, Ruth. Algumas idéias sobre a masculinidade das ciências naturais. In: GERGEN, Mary M. (ed.) $O$ pensamento feminista e a estrutura do conhecimento. Rio de Janeiro, Rosa dos Tempos/Edunb, 1993, pp.21-36.

HUNT, Lynn. Apresentação: história, cultura e texto. In: HUNT, L. (org.) A Nova História Cultural. $2^{a}$ ed. São Paulo, Martins Fontes, 2001.

JACOBUS, Mary; FOX KELLER, Evelyn and SHUTTLEWORTH, Sally. Introduction. In: JACOBUS, M.; FOX KELLER, E. and SHUTTLEWORTH, S. Body/Politics: Women and the Discourse of Science. New York, Routledge, 1990.

JORDANOVA, Ludmilla. Nature Displayed. Gender, Science and Medicine 1760-1820. London/New York, Longman, 1999.

Sexual Visions. Images of Gender in Science and Medicine between the Eighteenth and Twentieth Centuries. Madison, The University of Wisconsin Press, 1989.

LAQUEUR, Thomas. Making Sex: Body and Gender from the Greeks to Freud. Cambridge, Harvard University Press, 1990.

LAWRENCE, C. \& SHAPIN, S. Science Incarnate. Historical Embodiments of Natural Knowledge. Chicago/London, The Univ. of Chicago Press, 1998.

LONGINO, Helen e DOEL, Ruth. Body, Bias and Behavior: A Comparative Analysis of Reasoning in Two Areas of Biological Science. Signs, 9, 1983, pp.207-227.

LOPES, Maria Margaret. "Vencer Barreiras" até quando? Aspectos da trajetória científico-política de Bertha Maria Júlia Lutz (1894-1976). In: SANTOS, Lucy Woellner dos; ICHIKAWA, Elisa Yoshie; CARGANO, Doralice de F. Ciência, Tecnologia e Gênero: desvelando o feminino 
Maria Margaret Lopes

na construção do conhecimento. Londrina-PR, IAPAR, 2006, pp.203232.

e COSTA, M. Conceição da. Problematizando ausências: mulheres, gênero e indicadores na História das Ciências. In: QUARTIM DE MORAES, Maria Lygia. (org.) Gênero nas fronteiras do Sul. Núcleo de Estudos Gênero - Pagu/Unicamp, Coleção Encontros, 2005, pp.75-83.

; SOUSA, Lia Gomes Pinto de e SOMBRIO, Mariana Moraes de Oliveira. A construção da invisibilidade das mulheres nas ciências: a exemplaridade de Bertha Maria Júlia Lutz (1894-1976). Gênero, NUTEG, vol. 5, $2^{\circ}$ sem/2004, pp.97-109.

Mulheres e Ciências no Brasil: uma história a ser escrita. In: PÉREZ SEDEÑO, E. \& ALCALÁ CORTIJO, P. (coords.) Ciência $e$ Gênero. Madrid, Facultad de Filosofia, Um. Complutense de Madrid, 2001, pp.53-67.

"Aventureiras" nas ciências: refletindo sobre gênero e história das ciências no Brasil. Cadernos Pagu (10), Núcleo de Estudos de Gênero - Pagu/Unicamp, 1998, pp.345-368.

LÖWY, Ilana. Universalidade da ciência e conhecimentos "situados". Cadernos Pagu 15, Núcleo de Estudos de Gênero - Pagu/Unicamp, 2000, pp.15-38.

KOHLSTEDT, Sally Gregory and LONGINO, Helen. The Women, Gender and Science Question. What Do Research on Women in Science and Research on Gender and Science Have to Do with Each Other? Osiris 12, 1997,pp.3-15.

KUHN, Thomas S. Structure of Scientific Revolutions. Chicago, University of Chicago Press, 1962.

MARTENSEN, Robert. A transformação de Eva: os corpos das mulheres, medicina e cultura no início da Inglaterra moderna. In: PORTER, Roy e TEICH, Mikulás. (orgs.) Conhecimento sexual, ciência sexual. A história das atitudes em relação à sexualidade. São Paulo, Editora da UNESP, 1998, pp.133-162.

MARTIN, Emily. The Woman in the Body: A Cultural Analysis of Reproduction. Boston, Beacon Press, 1987.

MASTERMAN, Margaret. A natureza do paradigma. In: LAKATOS, Imre e MUSGRAVE, Alan. A crítica e o desenvolvimento do conhecimento. 
Sobre convenções

[Atas do Colóquio Internacional sobre Filosofia da ciência, Londres, 1965, vol. 4.] São Paulo, Cultrix/EDUSP, 1979, pp.72-108.

MERCHANT, Caroline. The Death of Nature: Women, ecology and the scientific revolution. San Francisco, Harper and Row, 1980.

OAKLEY, Ann. Sex, Gender and Society. London, Maurice Temple Smith, 1972.

ORESKES, Naomi. Objectivity or Heroism? On the Invisibility of Women in Science. OSIRIS: Science in the Field 11, 1996, pp.87-113.

OUDSHOORN, Nelly. On Bodies, Technologies, and Feminisms. In: CREAGER, A.N.H.; LUNBECK, E.; SCHIEBINGER, L. (eds.) Feminism in Twentieth-century Science, Technology, and Medicine. Chicago/London, The University of Chicago Press, 2001, pp.199213.

Beyond the Natural Body: an archeology of sex hormones. London, Routledge, 1994.

PICKSTONE, John V. Museological Science? The place of the analytical/ comparative in nineteenth-century Science, Technology and Medicine. History of Science, XXXII, 1994, pp.111-132.

PISCITELLI, Adriana. Re-criando a (categoria) mulher?. In: ALGRANTI, Leila Mezan. (org.) Textos Didáticos, n ${ }^{\circ} 48$ - A prática feminista e o conceito de gênero, Campinas-SP, IFCH/UNICAMP, novembro de 2002, pp.7-42.

ROSSITER, Margaret. Women Scientists in America. Struggles and Strategies to 1940. Baltimore/London, The Johns Hopkins University Press, 1982.

SHAPIN, S. The Scientific Revolution. Chicago, The University of Chicago Press, 1996.

SCHIEBINGER, Londa. Introduction: Feminism inside Sciences. Signs: Journal of Women in Culture and Society, vol. 28, Spring 2003. O feminismo mudou a ciência? Bauru-SP, EDUSC, 2001. Nature's Body. Gender in the Making of Modern Science. Boston, Beacon Press, 1993. The Mind Has No Sex? Women in the Origins of Modern Science. Cambridge/London, Harvard University Press, 1989. 
Maria Margaret Lopes

SHTEIR, Ann. Cultivating Women, Cultivating Science: Flora's Daughters and Botany in England, 1760 to 1860. Baltimore, Johns Hopkins University Press, 1996. 